\title{
0 CARNAVAL ELEGANTE DE FIGUEIREDO PIMENTEL
}

Fred Góes (UFRJ)

O presente artigo tem como tema central o carnaval da elite carioca no início do século XX, período conhecido como Belle Époque. Buscava-se seguir os padrões parisienses e londrinos de elegância, tendo entre nós como arauto da moda o jornalista Alberto Figueiredo Pimentel com sua coluna Binóculo na Gazeta de Notícias entre 1907 e 1914. Destaca-se como são tênues as fronteiras entre as formas de jogar o entrudo da elite e das classes populares.

ENTRUDO; ALBERTO FIGUEIREDO PIMENTEL; COLUNA BINÓCULO, CARNAVAL NA BELLE ÉPOQUE CARIOCA.

GÓES, Fred. O carnaval elegante de Figueiredo Pimentel. Textos escolhidos de cultura e arte populares, Rio de Janeiro, v.12, n.2, p. 21-31, nov. 2015. 


\section{THE ELEGANT CARNIVAL \\ OF FIGUEIREDO PIMENTEL}

Fred Góes (UFRJ)

This article is focused on the Carnaval of Rio's elite in the early twentieth century, a period known as Belle Époque. One north was to follow the Parisian and Londoner standards of elegance, having among us as fashion herald journalist Alberto Figueiredo Pimentel and his column in the Binóculo na Gazeta de Notícias between 1907 and 1914. We highlight the blurred nature of the boundaries between forms of playing the entrudo in elite and popular classes.

CARNIVAL; ALBERTO FIGUEIREDO PIMENTEL; COLUNA BINÓCULO; CARNIVAL IN THE CARIOCA BELLE EPOQUE.

GÓES, Fred. O carnaval elegante de Figueiredo Pimentel. Textos escolhidos de cultura e arte populares, Rio de Janeiro, v.12, n.2, p. 21-31, nov. 2015. 
É curioso que um indivíduo que teve extrema importância na vida da cidade do Rio de Janeiro na passagem do século XIX para o XX e nos primeiros anos deste último tenha caído em completo esquecimento em uma centúria. Um jornalista, cronista, poeta, escritor que vivia no olho do furacão da vida intelectual e social da então capital federal foi relegado ao "oblívio", a morada do esquecimento. Em 2014 fez cem anos que Alberto Figueiredo Pimentel faleceu. A única celebração realizada em sua homenagem foi a Jornada Figueiredo Pimentel, um polígrafo na Primeira República, uma iniciativa do Centro de Letras e Artes da Universidade Federal do Rio de Janeiro e da Fundação Biblioteca Nacional, em agosto de 2014. A mim coube, na ocasião, apresentar uma comunicação sobre a relação dele com o carnaval carioca.

Antes, porém, de entrar na questão central deste artigo, julgo necessário apresentar esse que foi efetivamente um polígrafo (quem escreve acerca de matérias diversas) e que, em função de sua militância diária na Gazeta de Notícias, titular da famosa coluna Binóculo (1907-1914), nos deixou expressivo legado sobre a visão e o comportamento da elite daquele período com relação às celebrações carnavalescas.

Figueiredo Pimentel nasceu em Macaé em 11 de outubro de 1869 e faleceu no Rio de Janeiro em 5 de fevereiro de 1914, aos 45 anos. Aos 17 iniciara-se no jornalismo.

Ainda que o foco aqui esteja dirigido para o precursor do colunismo social entre nós, não se pode deixar de mencionar que foi ele o primeiro intelectual a se preocupar em popularizar o livro, por meio de edições mais acessíveis de autores clássicos.

Pimentel reuniu em 1896, Contos da Carochinha, 61 contos populares, morais e proveitosos, de vários países, traduzidos ou recolhidos diretamente da tradição oral, entre eles Histórias da Avozinha, Histórias da Baratinha, Contos de Fadas, Contos do Tio Alberto, Histórias do Arco da Velha. Nessa recolha, há contos de Perrault, Grimm e Andersen, fábulas, apólogos, alegorias, contos exemplares, lendas, parábolas, provérbios, contos jocosos, etc. As publicações infantis eram encomendadas pelo editor Pedro da Silva Quaresma, dono da Livraria do Povo, que se destacava na cena das livrarias e das casas editoriais do princípio do século XX, no Rio de Janeiro, pelo fato de ser um dos poucos donos de livraria e editora brasileiras, em um ambiente dominado pelos Garnier (francês), Francisco Alves (português) e Laemmert (alemão).

A importância de Figueiredo Pimentel no cenário da literatura infantil é extraordinária tanto pelo fato de possibilitar a leitura aos pequenos leitores em livros a preços accessíveis como, e principalmente, por escrever histórias aclimata- 
das no Brasil e em português falado no Brasil. Antes das publicações de Pimentel, as crianças pouco entendiam os textos escritos em português de Portugal, carregados de expressões inusuais no falar brasileiro.

É da lavra de Pimentel, e também encomenda de Quaresma, o popularíssimo entre as moçoilas Manual dos namorados, em que eram sugeridas técnicas de sedução e conquista. Anteriormente à produção de livros infantis, publicou, em 1893, o livro de poesias Fototipias, inscrevendo-se na primeira leva dos simbolistas vanguardeiros. Foi correspondente do Mercure de France, quartel-general dos simbolistas franceses, escrevendo Lettres Bresiliennes, sob o pseudônimo de Barão de Santo Alberto. Em prosa, no mesmo ano, lança o romance $O$ aborto, popular, escandaloso, considerado pornográfico, entre outras obras, como $\mathrm{O}$ suicida, de grande sucesso, e $O$ terror dos maridos, Um canalha, Livro mau. Como se observa, os temas e os títulos das obras eram estrategicamente escolhidos para atiçar a curiosidade do público, prenunciando os artifícios mercadológicos utilizados nos lançamentos dos best sellers contemporâneos.

A coluna mundana Binóculo tinha grande vivacidade, bom ritmo e por sua própria dinâmica se estruturava em flashes, fragmentos diversos, ainda que, frequentemente, quando um tema merecia maior atenção do colunista, ganhasse os contornos da crônica. Um recurso usado com regularidade para ambientar o leitor no dia enfocado era iniciar o texto com a descrição do tempo (cronos). Observa o autor tratar-se ou não de um dia bonito, as condições do céu, como bem se pode aquilatar no exemplo selecionado:

Dia sombrio de mormaço. Foi com surpresa que a população carioca despertou. Receava-se chuva. Isto é, transferência da Batalha de Confetti, da Festa dos Cordões. E o receio foi justificado. Choveu. Tudo transferido. Que pena! (GAZETA DE NOTíCIAS, 8/3/1908, p. 3).

Observe-se que o fato lamentado é a suspensão da batalha de confete empreendida pelas classes mais favorecidas. A ideia de festa dos cordões, expressão popular, ganha aqui conotação genérica do carnaval realizado em espaço público, não definindo o segmento social.

Binóculo era o termômetro comportamental da elite social que buscava estar up-to-date com as novidades de Paris e Londres. O que era sugerido na coluna era incorporado com tal rapidez e obediência, que, por ocasião da inauguração do Theatro Municipal, em 1909, não paravam de chegar cartas à redação da Gazeta, e senhoras e senhoritas mais aflitas iam pessoalmente se consultar com Pimentel sobre como se vestir, que acessórios usar na cerimônia inaugural. Em função de suas descrições minuciosas dos trajes das damas das altas rodas em sua coluna, há quem suponha ter sido também figurinista, já que seu olhar afiado 
e refinado distinguia sem titubear quem estava atento às novidades parisienses. Todas as quintas-feiras à tarde, perto da Travessa do Ouvidor, no epicentro da elegância carioca, diante da porta das redações das principais folhas diárias, acontecia um verdadeiro desfile das coquetes. Os juízes eram Figueiredo Pimentel e seu séquito, do qual fazia parte Paulo Barreto, o João do Rio. As observações de Pimentel, em estilo muito próprio e pretensioso, eram aguardadas com ansiedade pelos leitores da coluna. Vale sublinhar que àquela altura as notícias chegavam às redações, não se ia a sua busca. Quem efetivamente revolucionou a prática jornalística nesse sentido foi João do Rio que, enquanto flanava pela cidade, pelos mais diversos rincões, se alimentava da "alma encantadora das ruas" cariocas.

A Gazeta de Notícias era um jornal de elite que tinha público fiel e que contava em seu quadro de redatores com os intelectuais e jornalistas mais destacados então. Eram eles Guimarães Passos, Olavo Bilac, Emílio Menezes, Pedro Rabello, Viriato Correia, Paulo Barreto (João do Rio). A partir de 1907, ano em que é iniciada a coluna Binóculo, se torna a mais moderna das folhas diárias. Oferece maior número de fotos, suplementos literários, ilustrações em cores, entre outras novidades. Como jornal moderno que era, tinha necessidade de contar com um apologista das reformas empreendidas na cidade durante o governo de Rodrigues Alves, a partir de 1904, e que teve nas figuras do prefeito Pereira Passos e de Oswaldo Cruz seus mais destacados representantes. $O$ apologista em referência era o poeta e cronista Olavo Bilac. Mas, fazia-se ainda necessária uma seção que indicasse o que estava em acordo com a vida moderna, como se comportar e viver na "metrópole"; nesse caso a responsabilidade recaía sobre Figueiredo Pimentel, que desempenhou esse papel com grande desenvoltura, informando aos leitores como exercitar a vida metropolitana smart. É dele, por exemplo, a máxima que se torna o slogan da modernização da cidade "o Rio civiliza-se", como também "a ditadura do smartismo", que se refere ao modo "descolado", atualizado de viver e circular pelos lugares "certos" da cidade.

O presente pano de fundo teve como propósito localizar de que lugar vem a autoridade que se atribuiu a Figueiredo Pimentel para se tornar o ditador da moda e dos bons costumes tanto durante o ano quanto durante os dias de carnaval. Nos dias da folia as pessoas iam à redação da Gazeta trajando suas fantasias para se tornar notícia. Figueiredo Pimentel relata na quarta-feira 4 de março de 1907 ter recebido a visita de uma senhora com trajes de sevilhana e descreve pormenorizadamente a fantasia:

Vieram visitar-nos especialmente: Mme. $\mathrm{X}$ com rica fantasia de sevilhana de cetim amarelo, com saia incrustada de duas barras de renda negra de seda e corpinho (?), abotoada à frente por botões 
de ouro, com cinto do mesmo cetim amarelo e mangas curtas pelos cotovelos, acabadas em folhas de renda preta e com dois volantes de renda negra também; bolero preto todo bordado a ouro e guarnecido de pequeninas borlas douradas em toda a volta; mantilha de renda creme, muito grande, segura na cabeça por um travessão de ouro e brilhantes (GAZETA DE NOTícIAS, 4/3/1907, p. 2).

A minúcia da descrição permite-nos ter clara ideia do requinte com que as mulheres da elite se fantasiavam, evidenciando o quanto o carnaval era celebração importante na vida social do Rio de Janeiro.

Uma das personagens mais populares e misteriosas do carnaval carioca da Belle Époque era um cidadão que, durante os dias de folia, frequentava os bailes, os desfiles e também as redações dos principais jornais, conhecido pela alcunha de Dominó Azul. A personagem é citada por vários historiadores da festa. Destacava-se na cena carnavalesca por vender aos foliões poemas e pufes. Durante o ano, o tal indivíduo solicitava a poetas do quilate de Olavo Bilac que escrevessem os textos. Uma vez vendidos, o dinheiro arrecadado era entregue às obras de irmã Paula, uma freira benemérita que auxiliava os desvalidos e que acabou sinônimo de bondade extremada no falar carioca. No Binóculo da segunda-feira 9 de março de 1908, informa-nos Pimentel: "Comunica-nos o benemérito e carnavalesco Dominó Azul que irá esmolar para os pobres, no (?) e na praia". A fantasia de Dominó, composta de máscara, chapéu e grande capa, não permite o reconhecimento de quem a veste. É o traje ideal para quem deseja cair na folia sem ser identificado. Muitos eram os Dominós que em grupos visitavam as redações com o intuito de fazer pilhéria, fazer intriga e fofoca sobre pessoas públicas.

Pimentel raramente deixava de ser noticiado pela revista Fon-Fon. ${ }^{1}$ Reproduziam-se notícias dadas por ele em primeira mão ou era ele mesmo, ou sua coluna, objeto de comentários, como se pode aquilatar nas notas mundanas selecionadas. Cabe, porém, sublinhar, antes de transcrever a matéria, a informação de que, apesar da acirrada campanha contra o jogo do entrudo por parte das autoridades, de forma especial a partir de Pereira Passos, a prática considerada característica das classes menos privilegiadas, era useira entre os smarts.

Em Notas Mundanas da revista Fon-Fon lê-se:

Um dos divertimentos mais interessantes do passado Carnaval, foi, incontestavelmente, o inventado por alguns rapazes de espírito da nossa melhor sociedade, de fazer os olhos das senhoras o alvo preferido de suas bisnagadas.

Lucram com isto os especialistas em moléstias de olhos. Não podia haver nada de mais interessante (FON-FON, 48, 7/3/1908, p. 9). 
Na sequência das notas acima referidas são publicados dois tópicos que nos chamam a atenção. O primeiro refere-se ao fato de as redações não fecharem durante o carnaval, o que nos remete ao costume de assistir aos desfiles das grandes sociedades, dos blocos e ranchos das sacadas das folhas diárias. Remetenos também ao fato de ser a imprensa instância que desempenha papel fundamental na realização da própria festa, seja como promotora de concursos, patrocinando desfiles, promovendo exposições de estandartes das entidades carnavalescas, seja como divulgadora dos principais acontecimentos. Não é por outra razão que durante os festejos recebe inúmeros visitantes ilustres.

O Binóculo funcionou desesperadamente durante os três dias de Carnaval.

Consta que a Gazeta vai dar um número especial somente contando o nome das pessoas que passaram na Avenida durante os três dias.

Fon-Fon recebeu na sua redação a honrosa visita de muitos máscaras avulsos.

Entre as fantasias de luxo e espírito que nos visitaram destacamos as seguintes:

Dr. Araujo Jorge rica fantasia de dançarina do Moulin.

General Pinheiro Machado trazia apenas uma ondulada e basta cabeleira de poeta lírico.

Dr. Carlos Peixoto Filho apenas de... nariz postiço.

E muitas e muitas outras fantasias cuja descrição, se tentássemos fazer, tomaria todo o número de Fon-Fon (FON-FON, 48, 7/3/1908, p. 9).

No mesmo número da revista, em seção denominada Echos do Carnaval, vamos encontrar mais uma notícia que reforça a ineficácia da campanha de Pereira Passos contra o entrudo e o modo como a brincadeira era praticada pelos jovens intelectuais e das classes mais abastadas. Se antes foi dito que a novidade era espargir as bisnagas nos olhos das senhoritas, diz-se agora que eram os ouvidos o alvo. A nota segue observando sobre a fantasia de Pimentel na terça-feira gorda, o que reforça a ideia de que fantasiar-se, propor uma identidade outra durante os dias de folia, era quesito fundamental do carnaval de então.

Uma das coisas que mais admiração causou aos frequentadores da Avenida durante os três dias de Carnaval foi a mania up-to-date de Luiz Edmundo de bisnagar furiosamente os ouvidos das senhoras e senhoritas que passavam à mão. Consta-nos que vários especialistas em moléstias de ouvido vão, por este fato, fazer uma estrondosa ovação ao conhecido poeta. 
Figueiredo Pimentel andou no terceiro dia de carnaval deliciosamente fantasiado de cupido. Reconhecemo-lo imediatamente porque chegou-se ao nosso ouvido e suspirou um - você me conhece - tão melífluo e elegante que só podia ser ele (FON-FON, 48, 7/3/1908, p. 28).

Ainda que as notas aqui selecionadas nos deem testemunho de que a fronteira entre a brincadeira carnavalesca da elite e a "prática entrudeira do populacho" em espaço público era muito tênue, se é que existia, observa-se que há um segmento da imprensa que não perde oportunidade de carregar nas tintas da crítica ao carnaval popular, associando-o sempre ao primitivismo, aqui plenamente impregnado do significado de inculto. Além dos cordões, que parecem destoar na paisagem da cidade que se quer moderna e civilizada, os batuques causam repulsa por remeter à cota negra de nossa formação de identidade. De forma especial, é rejeitada a presença, na festa, de índios portando animais vivos, como cobras, e, possivelmente, outros empalhados, por trazer imediatamente à memória tempos coloniais e imperiais em que a nação estava associada à ideia silvícola, o que se torna inadmissível em tempos republicanos. Diz a nota assinada sob o pseudônimo Carioca:

O Carnaval de hoje resume-se na alegria primitiva dos "cordões" que enchem a Cidade, desde as lavouras de Irajá até o silêncio da Gávea de uma feição de primitividade que já não fica bem ao nosso feitio de Cidade supercivilizada.

Esses "índios", essas cobras vivas, esses batuques fazem-nos retroceder dezenas de anos, abrem na nossa vida de hoje uma grande pausa à nossa proclamada civilização.

E certo compreender que a largueza ampla das Avenidas se case com justiça com essa feição monótona das alegrias africanas.

E como seria deliciosa a alegria do Carnaval se Ihe tirassem essa expressão externa de folia do interior da África! (FON-FON, 48, 7/3/1908, p. 10).

Não sabia o nosso opiniático Carioca que sem "essa expressão externa de folia do interior da África" há muito o carnaval teria sucumbido entre nós.

Possivelmente, pelo fato de Figueiredo Pimentel estar sempre associado ao que havia de mais novo, mais moderno no modo de vida urbano no Rio de Janeiro, acabou-se por se atribuir a ele ou como sendo sugestão dele o surgimento de algumas expressões no carnaval, o que nem sempre é verdadeiro. Já li, por exemplo, em textos sobre o carnaval do princípio do século XX ou da Belle Époque carioca que teria sido Pimentel o criador das "batalhas de flores" na cidade. A informação não procede. Augusto Malta, ${ }^{2}$ por exemplo, fez registros fotográfi- 
cos dessa expressão carnavalesca antes de Pimentel tornar-se o ditador de moda da Gazeta de Notícias. Ainda pior é quando se repete em vários textos que foi Pimentel quem criou o corso. Realmente, ele sugeriu que se fizesse o passeio dos automóveis e carroças durante o carnaval no Campo de Santana como possibilidade de mais um espaço para o desfile que acontecia tanto na Avenida Central quanto na Avenida Beira-Mar; no entanto não é o "pai" da prática.

É muito provável que a confusão tenha sido gerada tendo como sustentação o fato de que a moda do corso pegou depois de as filhas do presidente Afonso Pena terem desfilado no carro oficial no Carnaval de 1907. A data coincide com o início de Binóculo e pode ter havido uma sugestão de Pimentel. Onde, porém, parece que reside efetivamente o equívoco é no fato da criação de um calendário da moda de como viver na cidade e que se refere aos hábitos cotidianos e não aos carnavalescos. No calendário, Pimentel sugere que as quartas-feiras tenham como ponto alto o desfile do corso por Botafogo. Esse corso por ele mencionado é o desfile dos automóveis, ainda poucos na cidade, que fazia as vezes de footing motorizado e ao qual as pessoas iam para ver e ser vistas. O que parece ter havido foi uma grande generalização.

Para cada dia da semana há uma sugestão, sempre ligada a uma atividade considerada moderna então. Fon-Fon transcreve o proposto por Pimentel, demonstrando grande apreço por noticiar antes mesmo do autor:

\section{Calendário da moda}

O laureado autor do "Binóculo", a mais elegante das seções mundanas, está preparando um excelente calendário que determinará a vida "smart" durante sete dias da semana. É uma ideia engenhosa e de grande utilidade e "Fon-Fon" rejubila-se por ter merecido do ilustre elegante a honra de ser o primeiro... a publicar o calendário.

Como todo mundo sabe, Figueiredo Pimentel já havia distinguido três dias da semana com a realização das festas da moda: terça e sexta-feiras, visita aos cinematógrafos e quartas-feiras "Corso em Botafogo".

Pensando melhor, resolveu, porém, o ilustre "smart" distribuir uma festa da moda para cada dia da semana, de maneira que nossa alta sociedade não tenha muito trabalho em procurar ocupações para cada dia.

Publicamos, portanto, gostosamente o Calendário da moda.

Segunda-feira: É o dia destinado aos passeios de bond. Todo smart deverá andar de bond o dia inteiro, escolhendo de preferência o Bond no 37 da linha Humaitá. Fica assim entendido que a Festa 
da Moda de segunda-feira é andar a gente no Bond 37 da linha Humaitá.

Terça-feira: Este dia terá duas festas da moda; à noite sessão de cinematógrafo; de dia, até as cinco horas, todo smart deve estacionar à porta do Restaurant "Fransiskaner".

Quarta-feira: "Corso" em Botafogo e descanso à noite.

Quinta-feira: Five o'clock, em casa de Pimentel. Todo o smart (homem ou mulher) tem neste dia a rigorosa obrigação de tomar um trem de subúrbio e ir dar com os costados na Piedade, a fim de gozar do chá das cinco, oferecido pelo conhecido jornalista.

Sexta-feira: Cinematógrafo à noite.

Sábado: Durante o dia, passeio na Avenida Central, a pé, de carro, de automóvel ou de tilbury. À noite, rendez-vous no Leme e...banho de mar.

Domingo: De manhã, leitura do número especial da "gazeta" durante o dia visita ao "Jardim Zoológico"... ou a qualquer outra família conhecida. À noite soirée no "Bar" de Botafogo (FON-FON, 11, 6/4/1909, p. 24).

Algumas informações aqui contidas são relevantes no que concerne ao que foi introduzido por Pimentel como moda. Exemplar é o chá das cinco no meIhor estilo inglês e que naturalmente não acontecia na residência do jornalista na Piedade, mas, nas confeitarias da cidade. Outra ideia supermoderna é o banho de mar no Leme. Fica evidente tanto pela proposta de passeio na linha do bonde que circulava pelo bairro quanto pelo término da semana com a soirée em Botafogo que este era o que havia de mais elegante em termos de moradia.

Ainda que de forma sucinta, o objetivo deste artigo foi indicar que no âmbito carnavalesco as distâncias entre as práticas da festa da elite e das classes populares em espaço público na Belle Époque do Rio de Janeiro estão muito mais presentes nos textos jornalísticos do que na fuzarca. Além disso, buscou-se minimizar a autoria de certas práticas carnavalescas atribuídas aqui, em particular, a Figueiredo Pimentel.

\section{NOTAS}

1 A revista Fon-Fon surgiu no Rio de Janeiro em 1907, sendo importante registro da sociedade do Brasil em vários aspectos durante a Belle Époque. O nome foi escolhido por ser uma onomatopeia do barulho das buzinas dos automóveis, que chegavam ao país, na época, e acabava por tornar-se sinônimo de modernidade. Vale ressaltar que a "brincadeira" do nome estendia-se aos títulos das colunas presentes na revista e também integrava os textos produzi- 
dos pelos jornalistas, por exemplo, coluna Caixa de Gazolina, pseudônimo D. Buzina, Chauffeur, entre outros.

2 Ver Ermakoff, 2009, p. 180-181.

\section{REFERÊNCIAS BIBLIOGRÁFICAS}

ERMAKOFF, George. Agusto Malta e o Rio de Janeiro de 1903-1936. Rio de Janeiro: G. Ermakoff Casa Editorial, 2009.

PIMENTEL, Figueiredo. Binóculo. Gazeta de Notícias. Rio de Janeiro 8/03/1908.

Fred Góes é professor doutor da Faculdade de Letras da UFRJ e pesquisador do CNPq.

Recebido em: 21/12/2014

Aceito em: 30/01/2015 
